\title{
Comparing type 1 and type 2 diabetes in pregnancy- similar conditions or is a separate approach required?
}

\author{
Lisa A Owens ${ }^{1,2^{*}}$, Jon Sedar ${ }^{1}$, Louise Carmody ${ }^{1,2}$ and Fidelma Dunne $e^{1,2}$
}

\begin{abstract}
Background: Pregnancy in women with type 1 (T1DM) or type 2 diabetes (T2DM) is associated with increased risk. These conditions are managed similarly during pregnancy, and compared directly in analyses, however they affect women of different age, body mass index and ethnicity.

Methods: We assess if differences exist in pregnancy outcomes between T1DM and T2DM by comparing them directly and with matched controls. We also analyze the effect of glycemic control on pregnancy outcomes and analyze predictive variables for poor outcome.

Results: We include 323 women with diabetes and 660 glucose-tolerant controls. T2DM women had higher BMI, age and parity with a shorter duration of diabetes and better glycemic control. Preeclampsia occurred more in women with T1DM only. Rates of elective cesarean section were similar between groups but greater than in controls, emergency cesarean section was increased in women with type 1 diabetes. Maternal morbidity in T1DM was double that of matched controls but T2DM was similar to controls. Babies of mothers with diabetes were more likely to be delivered prematurely. Neonatal hypoglycemia occurred more in T1DM than T2DM and contributed to a higher rate of admission to neonatal intensive care for both groups. Adverse neonatal outcomes including stillbirths and congenital abnormalities were seen in both groups but were more common in T1DM pregnancies. $\mathrm{HbA1C}$ values at which these poor outcomes occurred differed between T1 and T2DM.
\end{abstract}

Conclusions: Pregnancy outcomes in T1DM and T2DM are different and occur at different levels of glycemia. This should be considered when planning and managing pregnancy and when counseling women.

Keywords: Pregnancy, Type 1 diabetes, Type 2 diabetes

\section{Background}

Pregnancy for women with pre-gestational diabetes is high risk. There is an increase in morbidity for the mother and an increase in morbidity and mortality for the baby. To date many observational studies have examined pregnancy outcomes for women with type 1 and type 2 diabetes as a group [1,2]. Few studies however have compared the clinical outcomes between the two groups [3] or have compared either group to matched controls [4]. Results of studies done comparing the two groups have been conflicting. In clinical practice women

\footnotetext{
* Correspondence: lisaannowens@gmail.com

'Atlantic Diabetes in Pregnancy Programme, Galway, Ireland

${ }^{2}$ Galway Diabetes Research Centre, National University of Ireland, Galway,
} Ireland

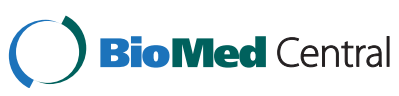

(c) 2015 Owens et al.; licensee BioMed Central. This is an Open Access article distributed under the terms of the Creative Commons Attribution License (http://creativecommons.org/licenses/by/4.0), which permits unrestricted use, distribution, and reproduction in any medium, provided the original work is properly credited. The Creative Commons Public Domain Dedication waiver (http://creativecommons.org/publicdomain/zero/1.0/) applies to the data made available in this article unless otherwise stated. with both conditions are treated in a similar manner, at the same clinics, with similar monitoring and treatment targets. However these two conditions have different pathologies, and affect two very different groups of women with different age, weight, ethnic background and duration of disease.

The aim of this retrospective case-control study was to examine pregnancy outcomes in women with type 1 diabetes and type 2 diabetes directly and compare pregnancy outcome of each group with matched normalglucose tolerant controls. Furthermore we aimed to assess if there are specific factors that predict poor outcome and if these predictive factors are different between the two groups. Finally we sought to assess if specific $\mathrm{HbA} 1 \mathrm{C}$ recordings in each trimester were predictive of good/poor 
outcome and if these HbA1C recordings are different in the two groups.

\section{Methods}

The Atlantic Diabetes in Pregnancy (DIP) program was established in 2007 and aims to provide evidence based care for women with Diabetes Mellitus before, during and after pregnancy. It has a dual role, providing clinical care as well as undertaking observational cohort studies aiming to enhance knowledge and improve management for women with Diabetes in pregnancy. It comprises 5 centers on the Irish Atlantic seaboard, with11000 deliveries annually.

All women with type 1 or type 2 diabetes for more than six months prior to the index pregnancy were included. Only singleton pregnancies were included. Women were managed within a multi-disciplinary service and were seen every two to four weeks throughout pregnancy. The multi-disciplinary team includes consultant diabetologist, consultant obstetrician, diabetes nurse specialist, midwife with an interest in diabetes and dietitian. Pre-pregnancy care (PPC) was offered to all women. This was done by letter and/or phone call. General practitioners and practice nurses were also informed via letter of the service and invited to refer women.

Normal glucose tolerance (NGT) controls were recorded as part of a cohort study of universal screening for gestational diabetes Mellitus (GDM) [5]. They had a normal 75 g Oral Glucose Tolerance test at 24-28 weeks gestation as defined by IADPSG [6] (International Association of the Diabetes and Pregnancy Study Groups). Written consent was obtained, as was ethical approval (Galway University Hospital Research Ethics Committee, Letterkenny General Hospital Research Ethics Committee, Mayo General Hospital Research Ethics Committee, Sligo General Hospital Research Ethics Committee). Two controls were included for each index case. Body Mass Index (BMI) was recorded at the first visit and at each subsequent visit. The first visit varied from 4 to 25 weeks but the average was at 15 weeks gestation.

All demographic data, treatment and outcomes were recorded electronically. Recorded data included age, ethnic group, gravidity, parity, family history of diabetes, folic acid use, smoking status, body mass index (BMI) preeclampsia, pregnancy induced hypertension, need for neonatal unit care (NNU), polyhydramnios, neonatal hypoglycemia, jaundice or hypocalcemia, elective or emergency cesarean section, instrumental delivery, miscarriage, stillbirth and congenital malformations. Blood pressure and weight were recorded at each visit and HbA1C was recorded at the first visit, in each trimester, and prior to delivery. HbA1c was measured by reverse phase cation exchange chromatography using the Menarini HA8160 automated haemoglobin analyser. The method was calibrated according to International Federation of Clinical Chemistry (IFCC) standardisation. Results are reported in IFCC and DCCT (Diabetes Control and Complications Trial) format.

\section{Obstetric/perinatal outcome definition}

Miscarriage was defined as pregnancy loss before viability (24 weeks gestation). Stillbirth was defined as loss of a viable fetus (after 24 weeks gestation). Preterm delivery was defined as before 37 weeks. Large for gestational age was defined as birthweight $\geq 90$ th centile, extreme large for gestational age as birthweight $\geq 97.7$ th centile and small for gestational age as birthweight $\leq 10$ th centile.

Gestational hypertension was defined as a blood pressure greater than $140 / 90$, without proteinuria, on two or more occasions greater than 6 hours apart, in a woman with normal blood pressure at her first obstetric visit. Preeclampsia was defined as blood pressure greater than $140 / 90$, with proteinuria, on two or more occasions greater than 6 hours apart after 20 weeks of gestation.

A composite of neonatal and maternal outcome was used in the statistical analysis. Maternal composite included: Preeclampsia, pregnancy-induced hypertension and emergency cesarean section. The neonatal composite included: stillbirth, miscarriage, premature delivery, polyhydramnios and neonatal hypoglycemia.

\section{Statistical analysis}

Statistical analysis was carried out using the $\mathrm{R}$ program. Chi-square and independent samples $T$-test were used for comparison between type 1 and type 2 and diabetes and controls. Controls were selected from a group of over 12000 women universally screened for gestational diabetes mellitus as part of a separate trial. Those with similar age, body mass index, parity and ethnic group to the group with diabetes were used. This was completed using cosine similarity matching with a customized nearest neighbors selection without replacement. Predictive modeling was done using classification tree based supervised learning. Significance level was set at a p-value of 0.05 .

\section{Results}

\section{Demographics (Table 1)}

323 women, 215 with T1DM and 108 with T2DM were included in this study and matched with 660 NGT controls. All but 3 women with T1DM were of Caucasian ethnicity, whereas 33 (31\%) of women with T2DM were of non-Caucasian ethnicity (two thirds of which were of Asian descent and one third black African). Women with T1DM were younger, with a lower gravidity and lower first recorded BMI and a longer duration of disease than women with T2DM. Attendance for pre-pregnancy care (PPC) occurred more commonly in women with 
Table 1 Demographic data of women with type 1, type 2 diabetes and controls

\begin{tabular}{llllll}
\hline Demographic & Type 1 diabetes & T1DM controls & Type 2 diabetes & T2DM controls & P value T1DM vs T2DM \\
\hline Total $\mathrm{n}=983$ & 215 & 447 & 108 & 213 & \\
Mean age & $31.9 \pm 5.6$ & $32 \pm 5.7$ & $33.7 \pm 4.8$ & $32.6 \pm 4.8$ & 0.0001 \\
Non-Caucasian ethnicity & $0.14 \%(\mathrm{n}=3)$ & $0.13 \%(\mathrm{n}=6)$ & $30 \%(\mathrm{n}=33)$ & $22 \%(\mathrm{n}=45)$ & 0.0001 \\
Mean first BMI $\left(\mathrm{kg} / \mathrm{m}^{2}\right)$ & $28.3 \pm 4.8$ & $28.4 \pm 4.9$ & $34.9 \pm 6.7$ & $33.2 \pm 6.2$ & 0.001 \\
Mean gravidity & $2.3 \pm 1.4$ & $2.3 \pm 1.5$ & $2.9 \pm 2.3$ & $2.7 \pm 1.7$ & 0.002 \\
Attended pre-pregnancy care & $44 \%$ & - & $34 \%$ & - & 0.02 \\
Pre-pregnancy folic acid use & $65 \%$ & $47 \%$ & $55 \%$ & $43 \%$ & $\mathrm{~ns}$ \\
Mean duration of Diabetes (years) & $14 \pm 8.2$ & - & $4.3 \pm 3.8$ & - & 0.001 \\
\hline
\end{tabular}

T1DM compared to T2 DM. Folic acid was used prepregnancy in $65 \%$ of women with T1DM and 55\% with T2DM.

\section{Glycemic control (Table 2)}

Trimester specific mean $\mathrm{HbA} 1 \mathrm{C}$ values are seen in Table 2. Overall the mean HbA1C in pregnancy is lower in women with T2 compared to T1 DM (5.8 vs. 6.6\%, $\mathrm{p}=0.001)$. In each trimester and prior to delivery mean $\mathrm{HbA} 1 \mathrm{C}$ is also significantly lower in women with T2 compared to $\mathrm{T} 1 \mathrm{DM}$ and in both groups $\mathrm{HbA} 1 \mathrm{C}$ improves as pregnancy progresses reaching a nadir of $6.4 \%$ and $5.7 \%$ in women with T1 and T2 DM respectively at term. Women who attended PPC in either group had a lower first trimester HbA1C compared to those who did not attend. Women who attended pre-pregnancy care had a lower mean first trimester $\mathrm{HbA} 1 \mathrm{C}$ recorded (T1DM $7 \pm 1 \%$ vs $8.4 \pm 1.8 \%$, T2DM- $7.3 \pm 1.8 \%$ vs $6.4 \pm 1 \%, \mathrm{p}=0.001)$.

\section{Maternal outcomes (Table 3)}

Preeclampsia (PET) occurred more commonly in women with T1DM compared to matched controls while women with T2DM and their matched controls had a similar prevalence of $8 \%$. On the other hand the rate of gestational hypertension (GH) was similarly increased in T1 and T2 women compared to controls. Elective cesarean

Table 2 Mean HbA1C values during pregnancy for type 1 and type 2 diabetes

\begin{tabular}{llll}
\hline Pregnancy stage & $\begin{array}{l}\text { Type 1 diabetes } \\
(\% \pm \mathrm{SD} / \mathrm{mmol} / \mathrm{mol})\end{array}$ & $\begin{array}{l}\text { Type 2 diabetes } \\
(\% \pm \mathrm{SD} / \mathrm{mmol} / \mathrm{mol})\end{array}$ & P value \\
\hline $\begin{array}{l}\text { Overall mean } \\
\text { HbA1C }\end{array}$ & $6.6 \% / 49$ & $5.8 \% / 40$ & $<0.0001$ \\
Trimester 1 & $7.7 \pm 1.6 / 61$ & $6.9 \pm 1.7 / 52$ & 0.0007 \\
$\begin{array}{l}\text { \% with HbA1C }<7 \% \\
\text { in T1 }\end{array}$ & $41 \%$ & $60 \%$ & 0.024 \\
Trimester 2 & $6.7 \pm 1.1 / 50$ & $6.1 \pm 1.1 / 43$ & $<0.0001$ \\
Trimester 3 & $6.4 \pm 0.95 / 46$ & $5.9 \pm 0.67 / 41$ & 0.0004 \\
Term & $6.4 \pm 0.88 / 46$ & $5.7 \pm 0.45 / 39$ & 0.02 \\
\hline
\end{tabular}

section (CS) was similarly increased in women with T1 and T2 DM compared to matched controls. Emergency CS was increased only in women with T1DM. Polyhydramnios was increased only in women with T1 DM compared to controls but rates were similar in women with T2 DM compared to controls. Ante- and postpartum hemorrhage were not different between groups and controls. Overall composite maternal morbidity was twice as common in women with T1 DM but not significantly different in women with T2 DM when compared to matched controls.

\section{Neonatal outcomes (Table 3)}

Babies born to mothers with T1DM and T2 DM were more likely to be delivered before 37 completed weeks of gestation when compared to matched controls. There was no difference in mean birth weight between groups $(3.54 \mathrm{~kg})$ and controls. There was an increase in babies born $>4 \mathrm{~kg}$ to women with T1DM compared to matched controls. Neonatal hypoglycemia was more prevalent in offspring of both T1 DM and T2 DM pregnancies when compared to matched-controls and higher in offspring of T1DM than T2DM. Hypocalcemia, neonatal jaundice, shoulder dystocia and polycythemia were similar between groups and matched controls. These however are relatively rare outcomes and the numbers in this study are too small to detect significant differences in these outcomes. The stillbirth rate was higher in babies of T1DM mothers compared to controls, but no difference was seen in mothers with T2 DM. Stillbirth occurred due to major malformation in 1 case and the results of post mortem are not recorded in our database. Congenital anomalies were higher in T1DM than controls, but the difference did not reach statistical significance $(p=0.07)$. Malformations that occurred were mainly classical ones seen with maternal diabetes and included; cardiac transposition $(n=3)$, ventricular septal defect $(n=3)$, atrial septal defect $(n=1)$, hydrocephalus $(n=1)$, cystic kidney $(n=1)$, rectal atresia $(n=1)$, missing tibia $(n=1)$, esophageal fistula $(n=1)$, sacral agenesis $(n=1)$ and caudal regression syndrome $(n=1)$. 
Table 3 Maternal and neonatal outcomes for women with type 1 and type 2 diabetes in pregnancy and controls

\begin{tabular}{|c|c|c|c|c|c|c|c|}
\hline Outcome/variable\% (n) & Type 1 diabetes & Matched control & P-value & Type 2 diabetes & Matched control & P-value & $P$ value T1DM vs T2DM \\
\hline$N=983$ & 215 & 447 & & 108 & 213 & & \\
\hline Pre-pregnancy folic acid & $65 \%$ & $47 \%$ & 0.001 & $55 \%$ & $43 \%$ & 0.06 & 0.10 \\
\hline \multicolumn{8}{|l|}{ Maternal outcomes } \\
\hline Preeclampsia & $12 \%(12)$ & $4.3 \%(19)$ & .0003 & $8.3 \%(9)$ & $8 \%(17)$ & 1 & 0.4 \\
\hline Gestational hypertension & $20 \% / 43$ & $10 \%(45)$ & .0003 & $22 \%(24)$ & $11 \%(23)$ & .014 & 0.8 \\
\hline Emergency section & $29 \% / 92$ & $16 \%(72)$ & .0002 & $17 \%(18)$ & $15 \%(32)$ & .86 & 0.08 \\
\hline Elective section & $30 \% / 65$ & $15 \%(67)$ & .002 & $36 \%(39)$ & $19 \%(40)$ & .002 & 0.3 \\
\hline Maternal composite* & $46.5 \%$ & $25 \%$ & .08 & $38 \%$ & $29 \%$ & .16 & 0.17 \\
\hline \multicolumn{8}{|l|}{ Neonatal outcomes } \\
\hline Miscarriage & $11 \%$ & $N / A^{* *}$ & & $8.3 \%$ & $N / A^{* *}$ & & 0.5 \\
\hline Stillbirth & $2.8 \%(6)$ & $0.4 \%(2)$ & .027 & $1.9 \%(2)$ & $0.9 \%(2)$ & .86 & 0.5 \\
\hline Neonatal deaths & 0 & 0 & & 0 & 0 & & \\
\hline Live birth rate & $85.6 \%$ & $99 \%$ & .0001 & $90 \%$ & $97.7 \%$ & .012 & 0.25 \\
\hline Congenital malformation & $4.2 \%(9)$ & $1.6 \%(7)$ & .074 & $2.8 \%(3)$ & $1.9 \%(4)$ & .90 & 0.74 \\
\hline Polyhydramnios & $10 \%(22)$ & $1.8 \%(8)$ & .001 & $6.5 \%(7)$ & $5.6 \%(12)$ & .95 & 0.36 \\
\hline Neonatal hypoglycemia & $20 \%(43)$ & $0.4 \%(2)$ & .0001 & $6.5 \%(7)$ & $0.5 \%(1)$ & 0.004 & 0.002 \\
\hline Hypocalcemia & 0 & $0.2 \%(1)$ & 1 & 0 & 0 & 1 & \\
\hline Neonatal jaundice & $6 \%(13)$ & $5.4 \%(24)$ & 0.86 & $8.3 \%(9)$ & $4.7 \%(10)$ & 0.29 & \\
\hline Shoulder dystocia & $2.3 \%(5)$ & $1.1 \%(5)$ & 0.39 & $1 \%(1)$ & $0.5 \%(2)$ & 1 & \\
\hline Polycythemia & $0.9 \%(2)$ & $0 \%$ & 0.19 & $0.9 \%(1)$ & 0 & 0.72 & \\
\hline Mean (kg) & $3.54 \pm 0.6$ & $3.54 \pm 0.6$ & 1 & $3.52 \pm 0.8$ & $3.54 \pm 0.7$ & 1 & 1 \\
\hline Weight >4 kg (\%) & $30 \%$ & $21 \%$ & 0.03 & $20 \%$ & $24 \%$ & 0.4 & 0.08 \\
\hline Weight $>4.5 \mathrm{~kg}$ & $6.5 \%$ & $4 \%$ & 0.27 & $8.2 \%$ & $3.8 \%$ & 0.16 & 0.76 \\
\hline Large for gestational age & $24 \%$ & $17 \%$ & 0.07 & $20 \%$ & $22 \%$ & 0.9 & 1 \\
\hline Small for gestational age & $5.6 \%$ & $6.5 \%$ & 0.8 & $5.6 \%$ & $6.5 \%$ & 0.9 & 1 \\
\hline Delivery $<37$ weeks & $28 \%(60)$ & $5.4 \%(24)$ & .001 & $22 \%(24)$ & $8.5 \%(18)$ & .001 & 0.29 \\
\hline Neonatal Unit care & $55 \%$ & $14 \% \%$ & .0001 & $39 \%$ & $17 \%(36)$ & .0001 & 0.009 \\
\hline Antepartum hemorrhage & $0.9 \%(2)$ & $3 \%(13)$ & 0.14 & $0 \%$ & $3 \%(6)$ & 0.13 & 0.8 \\
\hline Postpartum hemorrhage & $2.8 \%(6)$ & $4.9 \%(22)$ & 0.28 & $3.7 \%(4)$ & $4.7 \%(10)$ & 0.9 & 0.9 \\
\hline Neonatal composite ${ }^{* * *}$ & $48 \%$ & $6.5 \%$ & .0001 & $32 \%$ & $10 \%$ & .06 & 0.008 \\
\hline
\end{tabular}

*Maternal composite: Preeclampsia, gestational hypertension, emergency cesarean section.

**N/A: Controls were screened for GDM at 24 weeks, i.e. beyond the date of possible miscarriage.

***Neonatal composite: Stillbirth, miscarriage, premature delivery, polyhydramnios, hypoglycemia.

There were no neonatal deaths. More babies of T1 than T2 DM mothers were admitted to the neonatal intensive care unit (NNU) compared to controls. The most common reasons for admission to NNU were hypoglycemia (29\% of admissions) and prematurity (27\%). Composite poor neonatal outcomes were significantly greater in offspring of T1 than T2 mothers compared to controls. Overall the live birth rate was significantly lower for babies born to women with both T1DM and T2DM compared to their matched controls and non- significantly lower in pregnancies of $\mathrm{T} 1$ compared to $\mathrm{T} 2$ women. There was no statistically significant difference in miscarriage rate between T1 and T2 women.

\section{Impact of glycemic control (Table 4)}

We analyzed the effect of HBA1C values throughout pregnancy on maternal and neonatal outcomes for both types of diabetes. We report the mean $\mathrm{HbA1C}$ for those who did or did not have the studied poor maternal and neonatal outcomes for both T1DM and T2DM. HbA1C values were significantly higher for women with T1DM who had gestational hypertension, polyhydramnios, emergency cesarean section, elective cesarean section during their pregnancy than it was for women with T2DM who had these outcomes. Maternal and neonatal composite poor outcomes also occurred at higher $\mathrm{HbA1C}$ values in T1DM than T2DM. 
Table 4 Impact of glycemic control- Mean HbA1C values of pregnancy in those having poor outcomes and those without poor outcomes for type 1 and type 2 diabetes

\begin{tabular}{llllll}
\hline $\begin{array}{l}\text { Outcomes } \\
\text { Mean HbA1C } \pm \text { SD \%/mmol/mol }\end{array}$ & $\begin{array}{l}\text { T1DM- } \\
\text { Poor outcome }\end{array}$ & $\begin{array}{l}\text { T1DM- } \\
\text { No poor outcome }\end{array}$ & $\begin{array}{l}\text { T2DM- } \\
\text { Poor outcome }\end{array}$ & $\begin{array}{l}\text { T2DM- } \\
\text { No poor outcome }\end{array}$ & $\begin{array}{l}\text { P value } \\
\text { T1DM vs T2DM } \\
\text { poor outcome }\end{array}$ \\
\hline Gestational Hypertension & $7.2 \%(55) \pm 1.2 \%$ & $6.8 \%(51) \pm 1.3$ & $6.4 \%(46) \pm 0.9$ & $6.2 \%(51) \pm 1.1$ & 0.027 \\
Pre-eclampsia & $7.2 \%(55) \pm 1.3$ & $6.8 \%(46) \pm 1.3$ & $6.3 \%(45) \pm 1$ & $5.8 \%(41) \pm 0.6$ & 0.003 \\
Emergency csection & $7.2 \%(55) \pm 1.3$ & $6.8 \%(51) \pm 1.3$ & $6 \%(39) \pm 1$ & $6.3 \%(42) \pm 1$ & 0.048 \\
Elective csection & $6.8 \%(51) \pm 1.1$ & $7 \%(53) \pm 1.4$ & $6.3 \%(45) \pm 0.8$ & $6.3 \%(45) \pm 1.1$ & 0.009 \\
Maternal composite & $7.2 \%(55) \pm 1.2$ & $6.7 \%(51) \pm 1.3$ & $6.2 \%(44) \pm 1$ & $6.3 \%(45) \pm 1$ & 0.017 \\
Neonatal Hypoglycemia & $7.1 \%(54) \pm 0.9$ & $6.3 \%(45) \pm 0.9$ & $6.7 \%(50) \pm 1.5$ & $5.9 \%(41) \pm 0.5$ & 0.55 \\
Miscarriage(trimester 1 HbA1C) & $7.8 \%(62) \pm 1.2$ & $6.8 \%(51) \pm 1.9$ & $7.7 \%(61) \pm 1.6$ & $6.2 \%(44) \pm 0.8$ & 0.5 \\
Stillbirth & $8.8 \%(73) \pm 1.3$ & $6.8 \%(51) \pm 1.3$ & $\mathrm{n} / \mathrm{a}(\mathrm{n}=1)$ & $\mathrm{n} / \mathrm{a}$ & $\mathrm{n} / \mathrm{a}$ \\
Premature delivery & $7.4 \%(57) \pm 1.5$ & $6.7 \%(50) \pm 1.2$ & $6.6 \%(49) \pm 1.4$ & $6.2 \%(44) \pm 0.8$ & 0.28 \\
Polyhydramnios & $7.1 \%(54) \pm 1.1$ & $6.8 \%(51) \pm 1.3$ & $6.7 \%(50) \pm 0.9$ & $6.2 \%(44) \pm 1.3$ & 0.01 \\
Congenital malformation & $7.1 \%(54) \pm 1.6$ & $7.5 \%(58) \pm 1.5$ & $6.4 \%(46) \pm 0.7$ & $7.3 \%(56) \pm 1.8$ & 0.38 \\
(trimester 1 HbA1C) & & & & $6.1 \%(43) \pm 0.7$ \\
Neonatal composite & $7.3 \%(56) \pm 1.4$ & $6.5 \%(47) \pm 1.1$ & $6.6 \%(49) \pm 1.3$ & 6.034 & \\
\hline
\end{tabular}

\section{Predictive variables}

We used classification tree analysis to predict pregnancy factors that predict poor maternal and fetal outcomes. We looked at these outcomes over the full pregnancy period and per trimester. We created a composite of poor maternal and poor fetal outcomes (see Table 3 for components of composite). In women with T1DM, predictive factors of poor maternal outcome were nulliparity, booking BMI $>27 \mathrm{~kg} / \mathrm{m}^{2}$ and trimester $1 \mathrm{HbAlC}$ of $>7.8 \% / 68 \mathrm{mmol} / \mathrm{mol}$. For those with $\mathrm{T} 2 \mathrm{DM}$, the only predictor was a booking BMI $>38 \mathrm{~kg} / \mathrm{m}^{2}$ but for those with this high BMI older age ( $>35$ years) conferred worse outcomes. Higher $\mathrm{HbA} 1 \mathrm{C}$ did not predict poor maternal outcome for T2DM. In women with T1DM, HbA1C of $>6.8 \% / 51 \mathrm{mmol} / \mathrm{mol}$ was the only clear predictor of composite poor fetal outcome and for those with T2DM the main predictive variable was hypertension.

\section{Discussion}

Type 1 and type 2 diabetes in pregnancy have been associated with high maternal morbidity $[1,4,7,8]$ as well as high neonatal morbidity and mortality $[9,10]$. These increasingly more common conditions complicate $1-3 \%$ of all pregnancies and the prevalence is rising due mainly to an increase in the incidence of type 2 diabetes [11]. We have published our efforts [12] to improve these outcomes through pre-pregnancy care programs and intensifying glycemic control. However the outcomes of pregnancies complicated by diabetes in our cohort of predominantly Caucasian women continue to be worse than their counterparts without diabetes. In order to try and isolate areas for potential improvement we wanted to assess whether the various outcomes in pregnancy were different in those with type 1 and type 2 diabetes. We felt this to be an important step in the process of providing optimal, individualized, evidence-based care for our women throughout pregnancy as well as accurate patient counseling for our women.

We address this by several different approaches combined (a) direct comparison (b) comparison with matched controls (c) predictive modeling of poor outcomes and (d) assessing outcomes based on $\mathrm{HbA1C}$ values.

Several observational studies have analyzed the outcomes for type 1 and type 2 diabetes as a group, compared with controls $[13,14]$ and in most centers and guidelines the management of diabetes during pregnancy are similar for both types [15]. As the incidence of both types of diabetes continues to increase [14]' full recognition of the risks and appropriate management of both conditions are paramount. There have been several studies comparing the two conditions with each other or with matched controls to assess if outcomes are similar in order to promote similar treatment approaches, however results have been conflicting ${ }^{1}$ [16-19], Our paper adds to the knowledge gap by looking at a large group of predominantly Caucasian women with mainly wellcontrolled diabetes, who have been provided intensive monitoring during pregnancy and a significant proportion of whom have received pre-pregnancy care. We also have the additional benefit of having a large cohort of women with normal glucose tolerance for comparison.

Lapolla et al. [18] published a paper in 2007 comparing outcomes with diabetes and the general Italian population. They recorded similar numbers of women receiving prepregnancy counseling to our group and similar outcomes 
for women with diabetes but they compared outcomes with the Italian population in general not a matched control population. Hillman et al. [3] published a paper from Spain comparing outcomes for type 1 and type 2 diabetes. They had similar levels of glycemic control to our groups however they recorded less large for gestational age deliveries, neonatal respiratory distress syndrome and cesarean sections in their type 2 pregnancies compared to the type 1 women. They recorded a higher rate of premature deliveries in both groups than our group. There is no information given about the ethnic origins of the group so this may explain the difference with regards to baby size. There was no information about folic acid use and no control group in this study. Roland et al. [19] found a higher rate of serious adverse outcome in those with type 2 than type 1 diabetes.

There has been one meta-analysis published comparing outcomes for diabetes subtypes [20]. This comprised 33 studies, with varying ethnicities and study numbers. They found overall no difference in outcomes, except a lower rate of cesarean section amongst women with type 2 diabetes. They were unable to find any variables as significant predictors of poor outcome but the author comments that the posthoc analysis had low statistical power given only a small number of the original studies were included.

Since this meta-analysis several recent studies have also compared outcomes between these two groups. Knight et al. [21] in the USA in 2012 and Murphy et al. [22] in the UK 2011 both found results similar to this study, with better outcomes for women with T2DM. However Handisurya and colleagues [23] from Austria in 2011 and Wahabi et al. [24] from Saudi Arabia in 2012 analysed 200 and 112 pregnancies respectively and both reported outcomes that were similar for T1DM and T2DM.

Many studies have shown a high incidence of hypertensive disorders of pregnancy amongst women with both types of diabetes $[1,2]$. Our study showed that the problem of PET occurs more in those with T1DM compared to controls but in T2DM and matched controls it occurred with similar frequency ( $8 \%$ of cases). This highlights the importance of using a control population as when compared with our general pregnant population PET rates differ between T2DM and controls. Gestational hypertension occurred with similar frequency in both $\mathrm{T} 1$ and $\mathrm{T} 2$ pregnancies.

Cesarean section deliveries are common in modern obstetric practice. They are not however without complication and surgical complications are more common in women with a higher body mass index [16] and those with diabetes [25]. We saw an overall increase in cesarean section rate, with more emergency cesarean sections completed for those with T1DM and more elective cesarean sections completed in both groups compared to controls. The higher emergency section rate in those with T1DM is likely a reflection of more congenital malformations, greater number of babies $>4 \mathrm{~kg}$, and more polyhydramnios and PET. This difference is important for accurately counseling women of their chances of requiring operative delivery.

Heavier birth weights have been shown amongst babies of women with diabetes. Heavier birth weight and macrosomia are associated with short and long term health complications [26,27]; birth trauma, shoulder dystocia, higher rate of cesarean section and in the long term obesity and dysglycemia [28]. The mean birth weights in our groups were similar, but there was a higher prevalence of birth weight greater than $4 \mathrm{~kg}$ in babies of mothers with type 1 diabetes compared to matched controls. This did not translate into any significant difference in rates of shoulder dystocia, however numbers were too small to prove a difference in this relatively rare complication.

Birth outcomes were less favorable for babies of women with type 1 diabetes, with a higher stillbirth a nonsignificantly higher congenital malformation rate $[17,29]$. This may be as a direct result of a longer duration of diabetes with more micro-vascular disease and less optimal glycemic status at the start of pregnancy with only $41 \%$ having an $\mathrm{HbA1C}<7 \%$ in trimester 1 . Micro-vascular disease has been demonstrated to compromise placental circulation and to increase risk of stillbirth and preeclampsia $[9,13]$. These outcomes are essential knowledge for physicians but again are important for accurately counseling women regarding the risks of diabetes on their pregnancy. These outcomes are in spite of almost $40 \%$ of women attending pre-pregnancy care. Pre-pregnancy care has been shown to lower morbidity and mortality for pregnancies complicated by diabetes [12].

The link between glycemic control and pregnancy outcome is strong. However what is less strong is the knowledge about what level of glycemic control is necessary to minimize poor outcome and if this level of glycemic control is the same for those with T1DM and T2DM. We saw that the HbA1C values achieved by women with T2DM were lower throughout the whole pregnancy period than it is for those with T1DM. The mean $\mathrm{HbA1C}$ values at which poor outcomes occurred were also lower for women with T2DM than they were for women with T1DM. The exact reason for this and whether it could have clinical practice implications is as yet unclear. Our hypothesis is that these are outcomes have multiple contributors beyond glycemic control; for example obesity, gestational weight gain, hypertension, ethnic origin. For those with T1DM the microvascular burden of a longer duration of diabetes likely also has a significant role in these worse outcomes [30]. Although 
further studies are necessary, it is important too to comment that high insulin doses required for tight diabetes control may result in higher weight gain during pregnancy and this might be adding insult to injury $[1,31]$.

\section{Conclusions}

Overall the known outcomes associated with pregnancies complicated by diabetes were seen in our study in women with both type 1 and type 2 diabetes with a strong relationship to glycemia. However poorer neonatal outcomes occurred more commonly in babies of mothers with type 1 diabetes. Early or pre-pregnancy BMI, gestational weight gain and attendance at prepregnancy care have also been shown to be significant contributors to pregnancy outcome and are factors that should be addressed. The higher prevalence of these risk factors in T2DM, especially high BMI, may counteract the positive effect of better glycemic control, resulting in pregnancy outcomes that are not dramatically better than that of T1DM. In our study there was a trend towards less preeclampsia, neonatal hypoglycemia, neonatal unit care and macrosomia in T2DM than in T1DM pregnancies. On the other hand gestational hypertension, elective cesarean section, stillbirth and congenital abnormalities were common problems to both types of diabetes. While the goals of treatment of diabetes during pregnancy are similar for both types, individual factors should be considered when estimating risk of poor outcomes, in order to accurately counsel patients.

\section{Competing interests}

The authors declare that they have no competing interests.

\section{Authors' contributions}

LO wrote and revised the manuscript and was part of the conception and design of the study. JS completed the statistical analysis and was involved in the design of the study. LC contributed to the concept of the study, and was involved in the acquisition of data and drafting the manuscript. FD supervised the study and was involved in all areas- study design, data acquisition, drafting and revising manuscript. All authors read and approved the final manuscript.

\section{Acknowledgements}

We thank the ATLANTIC-DIP collaborators and the women involved in our studies. None of the authors have any conflicts of interest to disclose. This work is funded by the Health Research Board of Ireland. The guarantor of this work is Professor Fidelma Dunne.

Received: 11 September 2014 Accepted: 11 March 2015 Published online: 27 March 2015

\section{References}

1. Persson M, Norman M, Hanson U. Obstetric and perinatal outcomes in type 1 diabetic pregnancies: A large, population-based study. Diabetes Care. 2009;32(11):2005.

2. Dunne FP, Avalos G, Durkan M, Mitchell Y, Gallacher T, Keenan M, et al. "ATLANTIC DIP: pregnancy outcome for women with pregestational diabetes along the Irish Atlantic seaboard". Diabetes Care. 2009;32(7):1205-6.

3. Hillman N, Herranz L, Vaquero PM, Villarroel A, Fernandez A, Pallardo LF. Is Pregnancy Outcome Worse in Type 2 Than in Type 1 Diabetic Women? Diabetes Care. 2006;29(11):2557-8.
4. Knight KM, Pressman EK, Hackney DN, Thornburg LL. Perinatal outcomes in type 2 diabetic patients compared with non-diabetic patients matched by body mass index. J Matern fetal Neonatal Med. 2012;25(6):611-5.

5. O'Sullivan EP, Avalos G, O'Reilly M, Dennedy MC, Gaffney G, Dunne F, et al. Atlantic Diabetes in Pregnancy (DIP): the prevalence and outcomes of gestational diabetes mellitus using new diagnostic criteria. Diabetologia. 2011;54(7):1670-5.

6. International Association of Diabetes, Pregnancy Study Groups Consensus Panel, Metzger BE, Gabbe SG, Persson B, Buchanan TA, et al. International association of diabetes and pregnancy study groups recommendations on the diagnosis and classification of hyperglycemia in pregnancy. Diabetes Care. 2010;33(3):676.

7. Macintosh MC, Fleming KM, Bailey JA, Doyle P, Modder J, Acolet D, et al. Perinatal mortality and congenital anomalies in babies of women with type 1 or type 2 diabetes in England, Wales, and Northern Ireland: population based study. BMJ. 2006;333:177

8. Sibai BM, Caritis S, Hauth J, Lindheimer M, VanDorsten JP, MacPherson C, et al. Risks of preeclampsia and adverse neonatal outcomes among women with pregestational diabetes mellitus. National Institute of Child Health and Human Development Network of Maternal-Fetal Medicine Units. Am J Obstet Gynecol. 2000;182(2):364.

9. Miller E, Hare JW, Cloherty JP, Dunn PJ, Gleason RE, Soeldner JS, et al. Elevated maternal hemoglobin A1c in early pregnancy and major congenital anomalies in infants of diabetic mothers. N Engl J Med. 1981;304(22):1331.

10. Sibai BM, Caritis SN, Hauth JC, MacPherson C, VanDorsten JP, Klebanoff M, et al. Preterm delivery in women with pregestational diabetes mellitus or chronic hypertension relative to women with uncomplicated pregnancies. The National institute of Child health and Human Development Maternal-Fetal Medicine Units Network. Am J Obstet Gynecol. 2000;183(6):1520.

11. Lawrence JM, Contreras R, Chen W, Sacks DA. Trends in the prevalence of preexisting diabetes and gestational diabetes mellitus among a racially/ethnically diverse population of pregnant women, 1999-2005. Diabetes Care. 2008;31(5):899.

12. Owens LA, Avalos G, Kirwan B, Carmody L, Dunne F. ATLANTIC DIP: closing the loop: a change in clinical practice can improve outcomes for women with pregestational diabetes. Diabetes Care. 2012;35(8):1669-71. doi:10.2337/dc12-0120

13. Tennant PW, Glinianaia SV, Bilous RW, Rankin J, Bell R. Pre-existing diabetes, maternal glycated haemoglobin, and the risks of fetal and infant death: a population-based study. Diabetologia. 2014;57(2):285-94. doi:10.1007/s00125-013-3108-5.

14. Feig DS1, Hwee J, Shah BR, Booth GL, Bierman AS, Lipscombe LL. Trends in Incidence of Diabetes in Pregnancy and Serious Perinatal Outcomes: A Large, Population-Based Study in Ontario, Canada, 1996-2010. Diabetes Care. 2014 Apr 4. [Epub ahead of print]

15. Committee ACOG. on Practice Bulletins. ACOG Practice Bulletin. Clinical Management Guidelines for Obstetrician-Gynecologists. Number 60, March 2005. Pregestational diabetes mellitus. Obstet Gynecol. 2005;105:675-85.

16. Clausen TD, Mathiesen E, Ekbom P, Hellmuth E, Mandrup-Poulsen T, Damm P. Poor Pregnancy Outcome in Women With Type 2 Diabetes. Diabetes Care. 2005;28(2):323-8.

17. Diabetes and pregnancy group, France. French Multicentric Survey of Outcome of Pregnancy in Women With Pregestational Diabetes. Diabetes Care. 2003;26:2990-3

18. Lapolla A, Dalfrà MG, Di Cianni G, Bonomo M, Parretti E, Mello G; Scientific Committee of the GISOGD Group. A multicenter Italian study on pregnancy outcome in women with diabetes. Nutr Metab Cardiovasc Dis. 2008 May;18 (4):291-7. Epub 2007 Apr 11.

19. Roland JM, Murphy HR, Ball V, Northcote-Wright J, Temple RC. The pregnancies of women with Type 2 diabetes: poor outcomes but opportunities for improvement. Diabet Med. 2005;22(12):1774-7.

20. Balsells M, Garcia-Patterson A, Gich I, Corcoy R. Maternal and fetal outcome in women with type 2 versus type 1 diabetes mellitus: a systematic review and meta-analysis. J Clin Endocrinol Metab. 2009;94:4284-91.

21. Knight KM, Thornburg LL, Pressman EK. Pregnancy outcomes in type 2 diabetic patients as compared with type 1 diabetic patients and non diabetic controls. J Reprod Med. 2012;57(9-10):397-404.

22. Murphy HR, Steel SA, Roland JM, Morris D, Ball V, Campbell PJ, et al. Obstetric and perinatal outcomes in pregnancies complicated by Type 1 and Type 2 diabetes: influences of glycaemic control, obesity and social disadvantage. Diabet Med. 2011;28(9):1060-7. 
23. Handisurya A, Bancher-Todesca D, Schober E, Klein K, Tobler K, Schneider B, et al. Risk Factor Profile and Pregnancy Outcome in Women with Type 1 and Type 2 Diabetes Mellitus. J Womens Health. 2011;20(2):263-71. doi:10.1089/jwh.2010.2033.

24. Wahabi HA, Esmaeil SA, Fayed A, Al-Shaikh G, Alzeidan RA. Pre-existing diabetes mellitus and adverse pregnancy outcomes. BMC Res Notes. 2012;5:496.

25. Dronge AS, Perkal MF, Kancir S, Concato J, Aslan M, Rosenthal RA. Longterm glycemic control and postoperative infectious complications. Arch Surg. 2006;141(4):375.

26. Evagelidou EN, Kiortsis DN, Bairaktari ET, Giapros VI, Cholevas VK, Tzallas CS, et al. Lipid profile, glucose homeostasis, blood pressure, and obesityanthropometric markers in macrosomic offspring of nondiabetic mothers. Diabetes Care. 2006;29:1197.

27. Ornoy A. Growth and neurodevelopmental outcome of children born to mothers with pregestational and gestational diabetes. Pediatr Endocrinol Rev. 2005;3:104.

28. Silverman BL, Rizzo TA, Cho NH, Metzger BE. Long-term effects of the intrauterine environment. The Northwestern University Diabetes in Pregnancy Center. Diabetes Care. 1998;21 Suppl 2:B142.

29. Greene MF. Spontaneous abortions and major malformations in women with diabetes mellitus. Semin Reprod Endocrinol. 1999;17:127.

30. Gonzalez-Gonzalez NL, Ramirez O, Mozas J, Melchor J, Armas H, Garcia-Hernandez JA, et al. Factors influencing pregnancy outcome in women with type 2 versus type 1 diabetes mellitus. Acta Obstet Gynecol Scand. 2008;87(1):43.

31. Egan AM, Dennedy MC, Al-Ramli W, Heerey A, Avalos G, Dunne F. ATLANTIC-DIP: excessive gestational weight gain and pregnancy outcomes in women with gestational or pregestational diabetes mellitus. J Clin Endocrinol Metab. 2014;99(1):212-9. doi:10.1210/jc.2013-2684.

\section{Submit your next manuscript to BioMed Central and take full advantage of:}

- Convenient online submission

- Thorough peer review

- No space constraints or color figure charges

- Immediate publication on acceptance

- Inclusion in PubMed, CAS, Scopus and Google Scholar

- Research which is freely available for redistribution 